This is an electronic reprint of the original article. This reprint may differ from the original in pagination and typographic detail.

Author(s): Fenyvesi, Kristof

Title: $\quad$ Bridges: A World Community for Mathematical Art

Year: $\quad 2016$

Version:

Please cite the original version:

Fenyvesi, K. (2016). Bridges: A World Community for Mathematical Art.

Mathematical Intelligencer, 38(2), 35-45. https://doi.org/10.1007/s00283-016-9630-

9

All material supplied via JYX is protected by copyright and other intellectual property rights, and duplication or sale of all or part of any of the repository collections is not permitted, except that material may be duplicated by you for your research use or educational purposes in electronic or print form. You must obtain permission for any other use. Electronic or print copies may not be offered, whether for sale or otherwise to anyone who is not an authorised user. 


\section{Bridges: A World Community for Mathematical Art}

\section{Kristóf Fenyvesi}

\section{Mathematical Art Reborn: Academic Gathering or Festival of the Arts?}

This is not the first time the Mathematical Communities column has featured the Bridges Organization: the 2005 conference $^{1}$, in the breathtaking Canadian Rocky Mountains at Banff, was described in these pages by Doris Schattschneider [Schattschneider, 2006], a regular Bridges participant and Escher-specialist. The 2005 conference saw the debut of Delicious Rivers, Ellen Maddow's play on the life of Robert Ammann, a postal worker who discovered a number of aperiodic tilings. ${ }^{2}$ Marjorie Senechal, The Mathematical Intelligencer's current editor-in-chief, served as Maddow's consultant. ${ }^{3} \mathrm{~A}$ theatre premiér at a conference on mathematics? A production performed by mathematicians, moonlighting as actors? But this is Bridges.

A quick look at the 2005 conference relays the "essence" of this scientific and artistic "happening" resembling a first-rate festival of the arts. True to its title, Renaissance Banff, the 2005 Bridges gave all members of its community, whether based in the sciences or the arts, the feeling that they had helped bring about a genuine rebirth. I use "community" in its most complete sense-including adults, children, artists, university professors, art lovers and local people-for the wealth of conference activities could only be accomplished through the participation of each and every individual present.

In addition to formal conference lectures and the theatre performance, the program included an international mathematical art exhibit, a mathematical music night, and a mathart workshop series developed for teachers by teachers. Groups constructed enormous mathematical art installations and models. Following the musical performance by professional musicians, many mathematicians and artists grabbed an instrument and continued playing, just as anyone could lend a hand in constructing a colossal installation. As members of a collective undertaking, Bridges participants experienced the joy of creating a colorful and unique mathematical art community in which layperson and expert worked side-by-side, as equal partners. ${ }^{4}$ And, as a result of negotiations initiated in Banff, the Journal of Mathematics and the Arts ${ }^{5}$-a periodical dedicated to examining connections between mathematics and the arts - was started in 2007, published by Taylor \& Francis, with the professional support of the Bridges community.

Schattschneider noted that "Mathematics creates art."; Mathematics is art."; "Mathematics renders artistic images."; "Hidden mathematics can be discovered in art."; "Mathematics analyzes art."; "Mathematical ideas can be taught through art." After eighteen consecutive years of Bridges gatherings, we can say that the inverses are also true: Art creates mathematics; Art is mathematics; Artistic images render mathematics; Hidden art can be discovered in mathematics; Art analyzes mathematics; Artistic ideas can be taught through mathematics. Together with the organization supporting these events, the Bridges conferences have established a two-way bridge, aiding transfer between mathematics and the arts that has a significant amount of traffic. 
From its beginnings in 1998, Bridges has advocated for mathematics as a core component of STEM (Science, Technology, Engineering, Mathematics) education. Years before the STEM acronym was even created [Christenson, 2011] and spread, Bridges had humanized it. The Bridges community has never had to expand its approach from STEM to STEAM (Science, Technology, Engineering, Arts and Mathematics): it has always included those aspects of the arts, design, creative thinking and artistic imagination so very necessary to, yet still so very lacking from many STEM projects today. From its inception Bridges has given the STEAM movement inspiration for a transdisciplinary and intercultural platform.

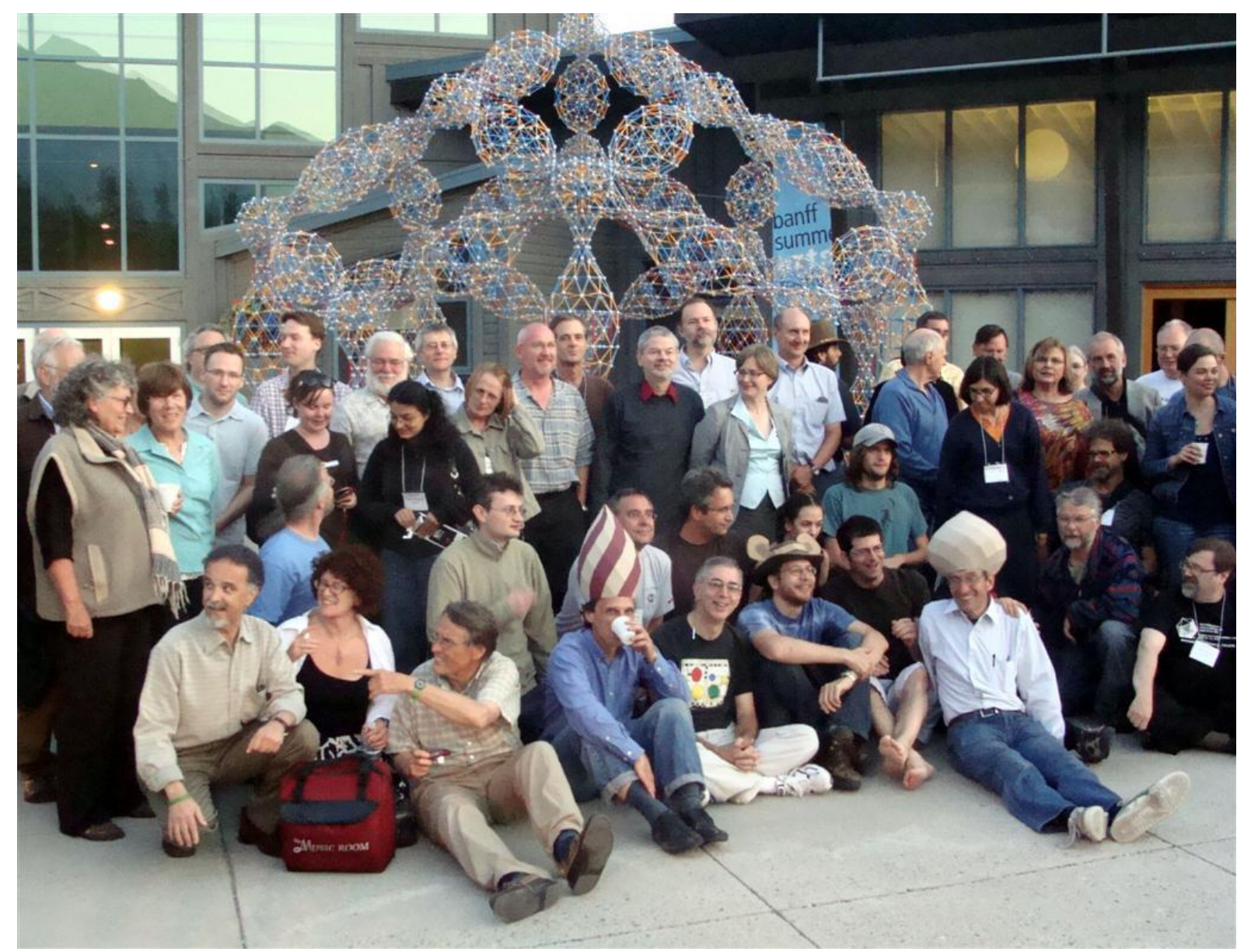

Figure 1: A colorful group of Bridges participants in front of the Gossamer Zometool model, a massive sculptural tribute to the late architectural visionary, Jean Christoph Kling, at the Bridges 2009 "Renaissance Banff II." conference. Five meters in diameter and assembled from 50,000 Tinkertoy-like parts, the gossamer model was the largest of its type ever attempted. 150 mathematicians and artists from all over the world and several of their children were assembling the small plastic Zometool components into superstructures that became the final sculpture. The work took more than 250 person-hours, performed during breaks between presenting and attending talks. Although the model is built entirely from points and straight lines (i.e., nodes and struts) the model looks like a 3-dimensional "spirograph" drawing, with organic curves that mimic life forms. The underlying structure is derived from a shadow of a 6-dimensional cube. Photo: Carlo H. Séquin. 
Accepted manuscript for The Mathematical Intelligencer, ISSN: 0343-6993 (print version) ISSN: 1866-7414 (electronic version) The final publication is available at Springer via http://link.springer.com/article/10.1007/s00283-016-9630-9 DOI 10.1007/s00283-016-9630-9

\section{From the "Persian Paradigm" to STEAM and Back Again: the Inception of Bridges}

The first few Bridges conferences were hosted by Southwestern College in Winfield, Kansas. How did this small town college, not known for its contributions to the art and science discourse, assume this role?

As is often the case with active and successful communities and networks, Bridges was begun by a many-sided individual with contacts in both science and culture. When Reza Sarhangi emigrated to the United States from Iran in 1986, at the start of his mathematical career, he brought with him the qualities associated with STEAM integration today. His broad range of personal interests as well as his research into ancient Persia's mathematical past helped him direct attention to mathematics' complex cultural roots. His work as a university teacher in education was defined by these goals as well. For his integrational approach to mathematics and art, Sarhangi looked far beyond the well-known works of artists such as M.C. Escher [Sarhangi and Martin, 1998.] to the joint efforts of mathematic and artistic communities in ancient times.

Mathematics, arts and crafts coexised side-by-side during the medieval period of Persian history. ${ }^{6}$ Sarhangi has continuously emphasized the work of Abul Wafa al-Buzjani (940997/998), one of the most famous mathematicians of his time. Al-Buzjani's treatise, On Those Parts of Geometry Needed by Craftsmen, was written to educate craftspeople in geometry. For medieval craftspeople, creating the decorative motifs common to the Persian art of this era demanded not only constant training, but also regular consultation with mathematicians. Indeed, decorating the inner as well as outer, spherical surface of cupola with tiles featuring highly regular, yet still extremely complex geometric patterns would have required advanced knowledge of geometry. The sophisticated, mathematical nature of Persian decorative arts not only makes them interesting from a historical perspective, but also provides a fascinating area of research for mathematicians today. ${ }^{7}$

Before emigrating to the United States, Sarhangi was more than a teacher of mathematics interested in Persian traditions. He was a graphic artist, teacher of drama, playwright, theatre director and props designer. When added to his background in mathematics and history, his first-hand experience of complex and collective artistic processes - such as creating and performing a theatrical play-gave him deep insight into the equally complex processes involved in designing and producing medieval Persian tilings. Sarhangi made good use of his many areas of expertise, first as an innovative, young university professor open to new experiments, then later on as an educator of math instructors. As department chair of Southwestern College's Department of Mathematics, he already introduced creative study modules or theatrical plays on mathematics to change how mathematicians were educated.

In his new country Sarhangi looked for the kind of academic community capable of supporting his broad range of interests. In the early 1990s, the college implemented a new Integrative Studies Program that drew together faculty from all other traditional and 
professional programs. As director of the Integrative Studies Program, Daniel F. Daniel, Sarhangi's close friend and mentor at Southwestern, suggested that Sarhangi establish a new course for this program. His course on connections between mathematics and the arts became very popular among students.

Sarhangi also attended the Art and Mathematics (AM) conferences organized by Nat Friedman at the State University of New York at Albany from 1992 to 1998, which opened their doors to artists, architects, and other experts applying mathematics creatively. The spirit of cooperation engendered by these AM gatherings led to the publication of several interdisciplinary papers uniting different perspectives to form a kaleidoscope-like vision of the given topic. With some exaggeration, it can be said that Sarhangi felt he was witnessing the rebirth of a long-forgotten paradigm from Abul Wafa al-Buzjani's time. He could see first-hand how a new form of art arises from the dialogue between the mathematician creating the theories for solving complex artistic or architectural problems, and the master putting theories into practice. This art possesses a unique, aesthetic quality all its own, whose analysis demands a new approach, a kind of "interdisciplinary aesthetics" both mathematical and artistic in nature. ${ }^{8}$

Known as ISAMA (International Society of the Arts, Mathematics, and Architecture) ${ }^{9}$ as of 1998, the AM movement was the direct, American antecedent to the later Bridges conferences. Indeed, three of Bridges's first four directors: George Hart ${ }^{10}$, Carlo Séquin ${ }^{11}$ and Reza Sarhangi were ISAMA veterans. The fourth director, Craig S. Kaplan ${ }^{12}$, started his career in mathematical art in 1999 after joining the ISAMA and Bridges communties and coorganizing the MOSAIC 2000 conference, which examined connections between computer programming and the arts. Robert $W$. Fathauer ${ }^{13}$ soon assumed responsibility for organizing the Bridges art exhibits. ${ }^{14}$ 


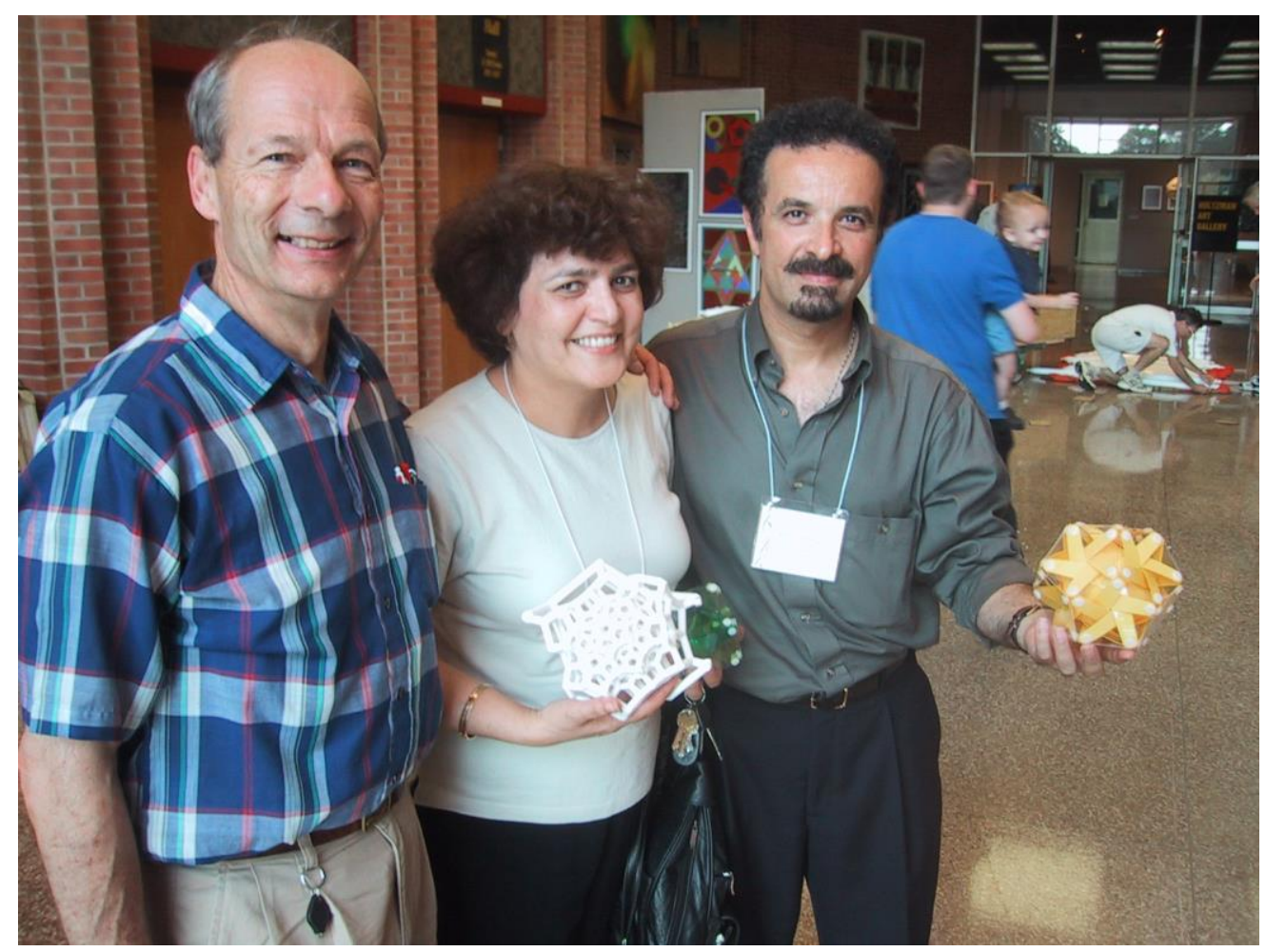

Figure 2: Bridges would not exist without them. Bridges Organization's founders Reza Sarhangi (right), Sarhangi's wife Mehri Arfaei (middle) and Carlo H. Séquin (left). Photo by courtesy of Reza Sarhangi.

Many groups and "schools" have connected to form the background for the American, European and Asian science and art communities currently involveld in the Bridges Organization. These include the Mathematics and Culture conferences [Emmer, 2004-2012, 2012-2014, 2015], the Nexus conferences, ${ }^{15}$ and the Symmetry Festivals ${ }^{16}$ begun by György Darvas and Dénes Nagy in 1989 in Budapest, Hungary. The increasingly active presence of the European Society of Mathematics and $\mathrm{Arts}^{17}$ also deserves mention. Bridges also enjoys a close-knit relationship with the International Mathematics \& Design Association located in Buenos Aires, established by the mathematician, Vera $W$. de Spinadel, in 1998 . The Mathematical Association of America's Special Interest Group on Mathematics and the Arts (SIGMAA-ARTS) was established by Bridges members and participants, and currently has more than 200 members. $^{18}$

\section{Inter- and Transdisciplinarity: Bridges as a "World View"}

The nearly 300-page proceedings from the first Bridges conference ${ }^{19}$ was reviewed in Nexus Network Journal by the mathematician, Solomon Marcus, a pioneer in numerous interdisciplinary as well as transdisciplinary areas related to mathematics [Marcus, 1999]. He called for the further broadening and deepening of artistic analysis within the newly- 
emerging, Bridges discourse to include, for example, connections between mathematics and poetry. The Bridges Organization has followed his suggestions. Year by year, as exhibits increasingly put new mediums of mathematical art on display, conference lectures open these works to further analysis. The movement's tendency to refine its themes inspires new program elements, such as the Bridges Poetry Afternoons organized by Sarah Glaz. ${ }^{20}$

Marcus noted that "[at the Bridges conferences] artists enlarge their creative horizon by looking at the achievements of modern science, while scientists have a chance to see, in a new light, their own results." [Marcus, 1999: 156.] And in fact many of the experiences and moments reflected in this conference series demonstrate art's ability to broaden the horizons of science as well. ${ }^{21}$

Probably the best evidence for the two-way traffic on Bridges' bridges is the many transdisciplinary collaborations which grown from encounters between mathematicians and artists at Bridges-related events. For example Ars Geometrica Symposiums (2007-2009, Hungary)-which prepared the ground for Bridges 2010 in Hungary-led to the international recognition of the mathematical artworks of sculptor István Böszörményi [Gailiunas 2007] and also sparked Böszörményi's still on-going collaboration with the renowned mathematician Lajos Szilassi, whose "Szilassi-polyhedron" was noted and popularized by Martin Gardner [Gardner, 1978]. Szilassi's mathematical theories and models have inspired the sculptor Böszörményi's art [Böszörményi 2013]. Artists also have fruitfully inspired mathematical research, as the case of the mathematician László Vörös and the artist Tamás F. Farkas shows [Vörös 2011].
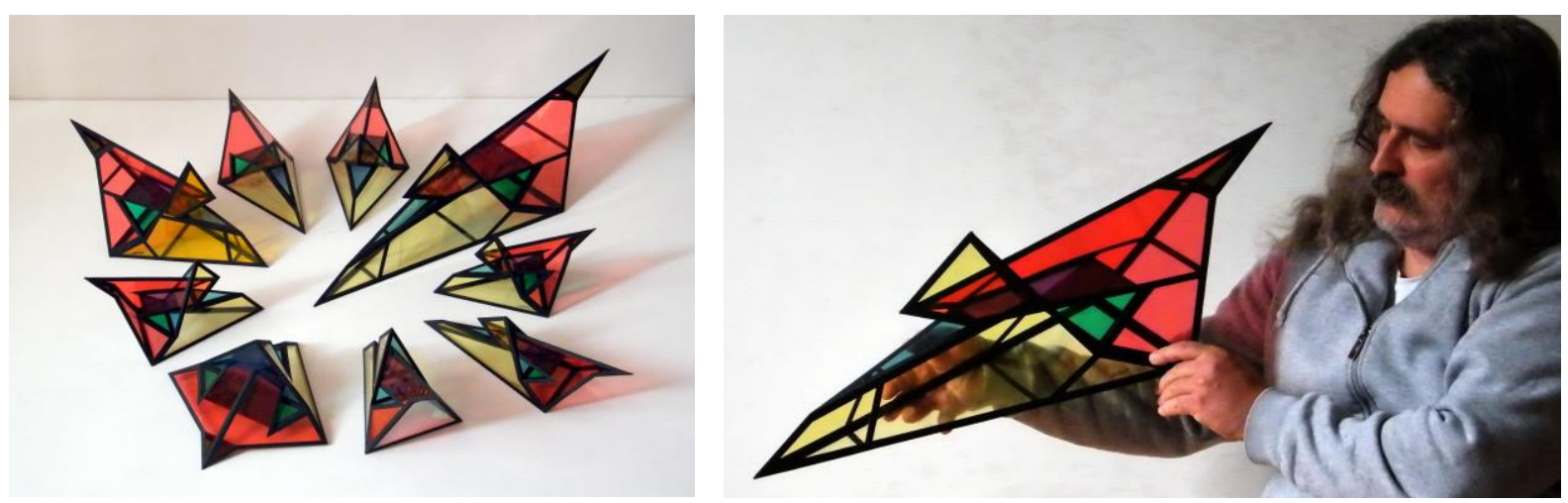

Figure 3 a, b: Hungarian sculptor, István Böszörményi and some of his mathematical artworks based on his collaboration with the mathematician, Lajos Szilassi 

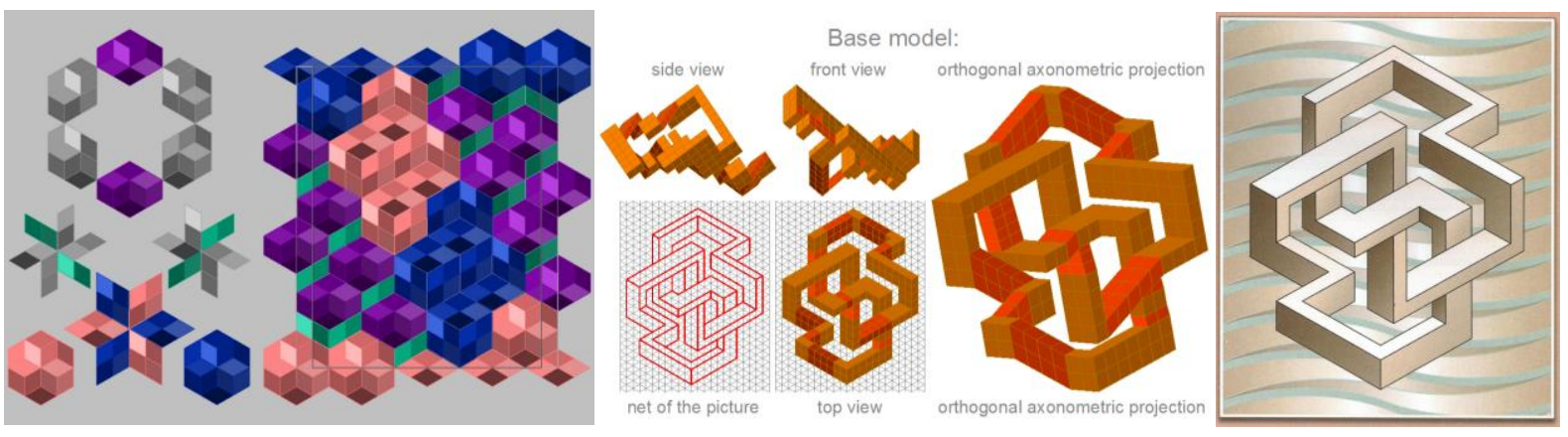

Figure 4 a, b, c: László Vörös' mathematical reconstruction of Victor Vasarely's Duo-2, 1967 (left), and Tamás F. Farkas' impossible figure (middle) based on the same method [cf. Vörös 2011], and Farkas' original artwork (right), which inspired Vörös' research.

From its beginning, Bridges has broken with the monotony of traditional conference lectures. The goal was to bring research alive, have it on display-or even put it on stage. Mathematician Mike Field-co-author of Symmetry in Chaos [Field and Golubitsky, 2009] described his experiences at the second and third Kansas conferences: "At the Winfield conferences, the international virtuoso violinist Corey Cerovsek played for the audience after plenary sessions in the morning, often preceding his performance with an extempore talk on a topic from physics or mathematics (concurrently with his musical studies, Corey completed all the coursework for a Ph.D. in mathematics when he was about sixteen). Aside from the music, there would usually be theater shows as well as teacher workshops, held at the end of the conference. [...] I [...] can testify to the great atmosphere of these meetings, where artists, mathematicians, computer scientists, and educators would talk into the early hours." [Field, 2006: 730.] Reza Sarhangi draws on his past in theatre to evoke the personable atmosphere and wealth of experiences at these first gatherings: "Theatre involves making connections with the audience that go beyond just the script [...] So at Bridges, I - and the other three board members - want the conference attendees to get more than just the content of the papers, but to have an enjoyable experience that integrates art, dance, and other performances." [Crease, 2014: 17.] 

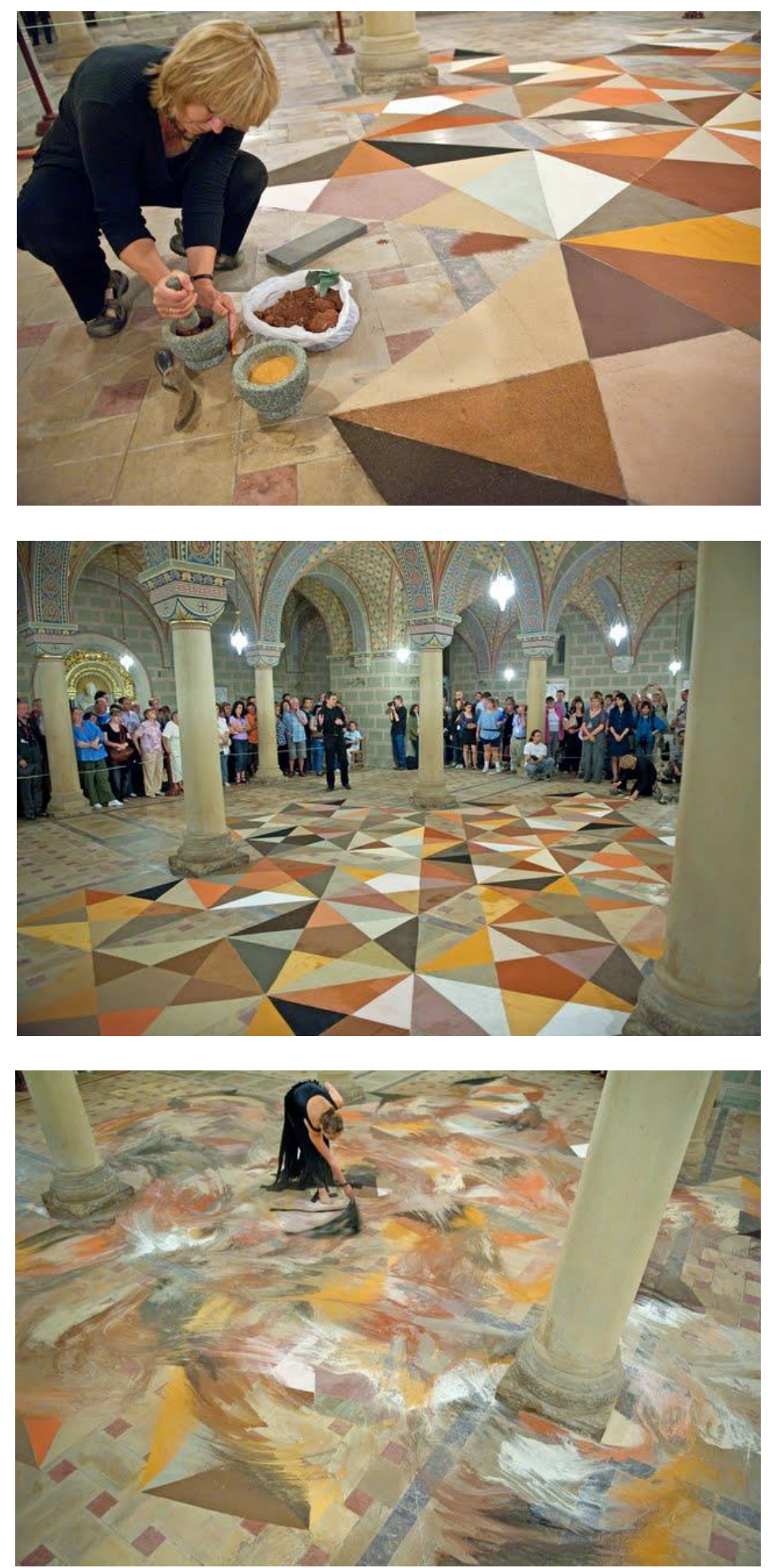

Figure 5 a, b, c: "Worldsand" (Sammlung Weltensand) composition at Bridges 2010 by Elvira Wersche, who collects different types and colours of sand from all over the world and uses it to construct complex mosaics, composed of geometrical patterns, on the floors of museums, churches and synagogues. When the artwork was finally ready, a dancer literally erased the carefully constructed pattern. By doing so, the artist emphasized that everything is in constant flux and everything is only temporary. Photos: László Mihály. 


\section{Bridges around the World}

Barely sixty participants attended the first Bridges conferences; today they attract annually around 250-300 conference participants from around the globe and thousands of people in the audience. Since Sarhangi moved from Winfield to Towson, Maryland, in 2002, the Bridges Organization - a Scientific and Educational Non-Profit Corporation established in the State of Maryland in 2006 - has handled the administrative tasks related to these events.

The resounding success of Bridges 2003 in Granada, Spain (organized together with ISAMA) -- in the shadow of the Alhambra, one of the greatest math-art works in history-prompted the organizers to hold future conferences in tourist destinations, and include thematic daytrips. Bridges conferences have been held in Winfield, USA (1998-2001); Towson, USA (2002) ; Granada, Spain (2003); Winfield, USA (2004); Banff, Canada (2005); London, UK (2006); San Sebastian, Spain (2007); Leeuwarden, The Netherlands (2008); Banff, Canada (2009); Pécs, Hungary (2010); Coimbra, Portugal (2011); Towson, USA (2012); Enschede, The Netherlands (2013); Seoul, Korea (2014); and Baltimore, USA (2015). In 2016 Bridges will embark on its first Nordic conference, held at the University of Jyväskylä in Finland, the most northern location ever to host a Bridges event. ${ }^{22}$

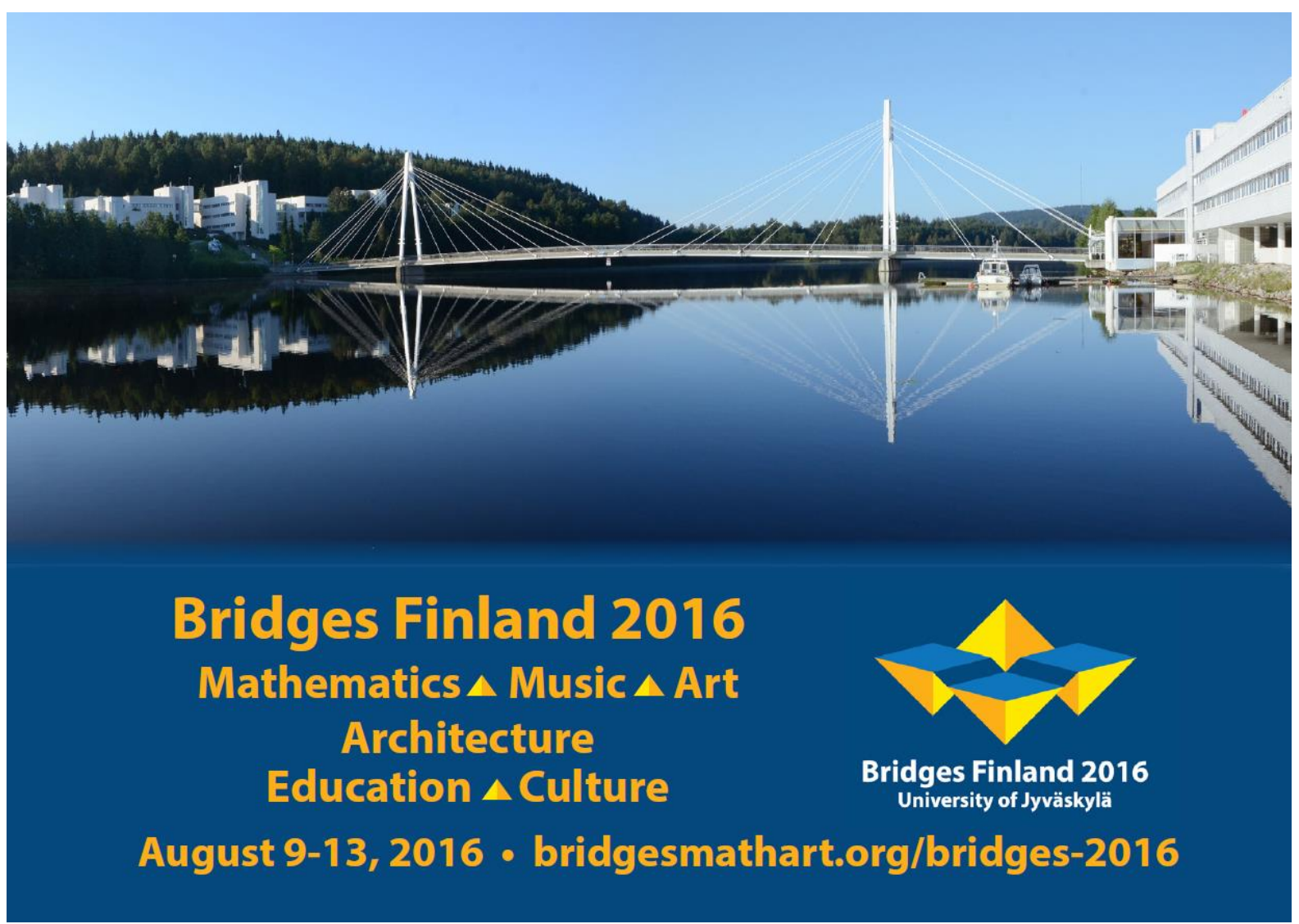

Figure 6: Invitation postcard for Bridges Finland 2016, hosted by the University of Jyväskylä. 
Once its community took to globe-trotting, the Bridges conferences began generating a form of organized math-art tourism. But the intellectual benefits extend beyond the conferenece participants. Thanks to international media, the attention paid Bridges events-hosted by resident scientific and cultural institutions-strengthens local math-art communities. I can attest that the Experience Workshop Math-Art Movement, ${ }^{23}$ an independent community of mathematicians, artists and educators, established in Hungary in 2008 preceding the Bridges Pécs 2010 conference, is still growing. Through this movement tens of thousands of Hungarian students and thousands of teachers have been exposed to the Bridges philosophy of experience-oriented mathematics education through the arts.

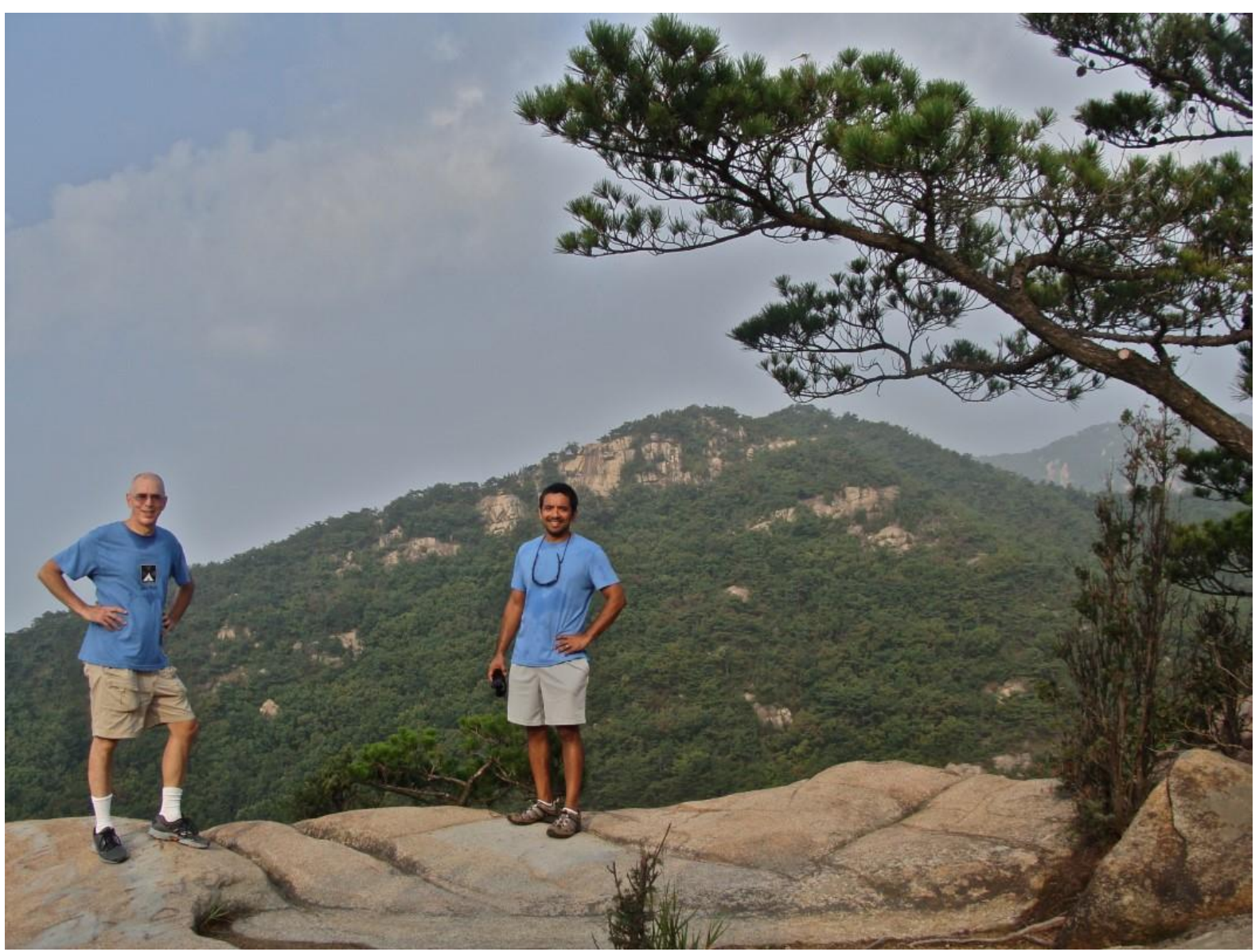

Figure 7: Top scholars - George W. Hart (left) and Sujan Shrestha (right) on Bridges Seoul 2014 conference excursion in the Korean mountains. Photo: Carlo H. Séquin. 


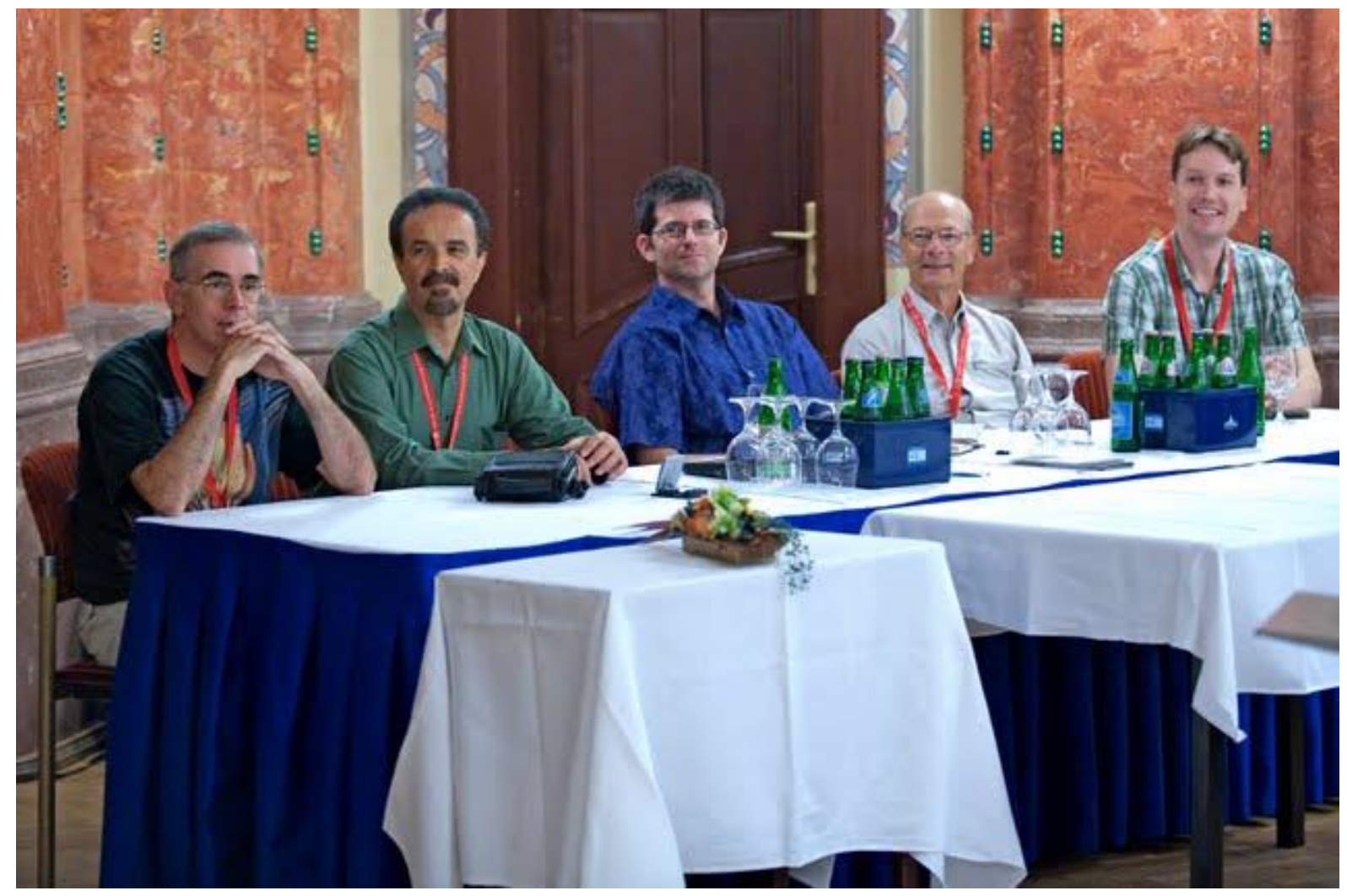

Figure 8: Bridges directors George W. Hart, Reza Sarhangi, Craig S. Kaplan, Carlo H. Sequin and Kristóf Fenyvesi (left to right) listening the talk of Rubik's cube's inventor, Ernö Rubik at Bridges Pécs 2010, Hungary. Photo: László Mihály.

\section{Participants, Goals and Events at Bridges Conferences}

The sheer diversity of topics and areas addressed at Bridges conferences draws a wide audience of scholars and artists. ${ }^{24}$ In addition to mathematicians, scientists, art and education experts, they attract painters, teachers, musicians, architects, literary scholars, computer programmers, sculptors, dancers, craftspeople and model builders. 


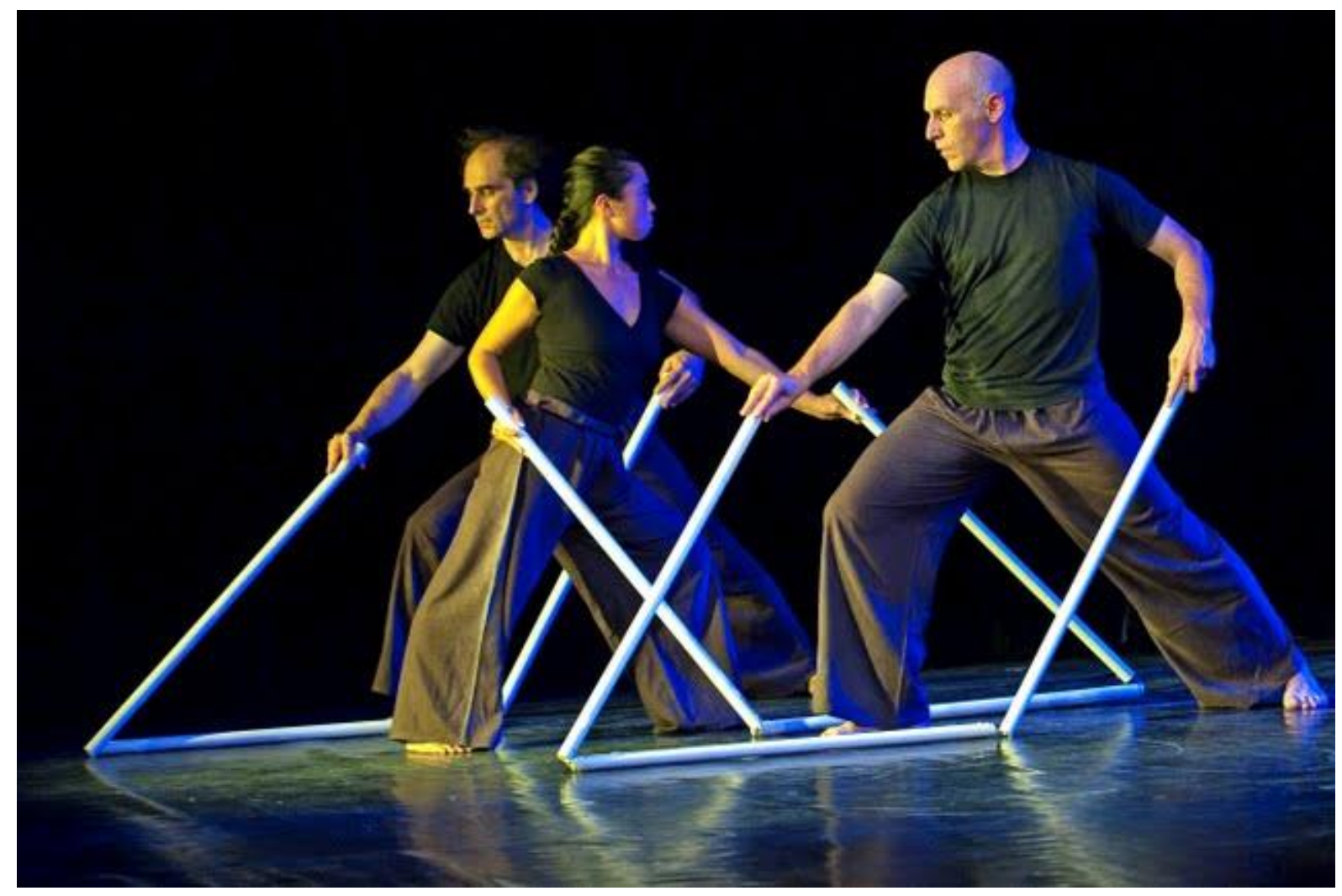

Figure 9: Dr. Schaffer and Mr. Stern Dance Ensemble's performance at Bridges 2010. Photo: László Mihály.

Each conference reflects many different aspects. Bridges presents a platform for scholars, experts and artists intent upon pushing boundaries and exchanging experiences. Beyond supplying professional support, it encourages mathematics teachers to utilize creative, artistic processes and tools in passing on mathematical knowledge, and art teachers to reveal the mathematics involved in certain artworks or artistic processes. The educational relevance of math-art approaches has been demonstrated in interactive, experienceoriented workshops since Bridges's early days. Works of art are displayed in math-art exhibits, not just discussed in conference lectures. The Bridges collection has since grown to be the largest exhibit of mathematical-art in the world. Throughout the years, creative programs have become increasingly structured and have now evolved into separate areas of expertise directed by skilled professionals. The key elements, which form the backbone of any Bridges event (such as the plenary and section lectures, education and fun workshops, mathematics and art short movie festival, the mathematical art exhibit, the mathematical theatre show, music night, family day, poetry afternoon, and public events) can be studied on the Bridges Organization's website, where each year's program is archived. ${ }^{25}$ 


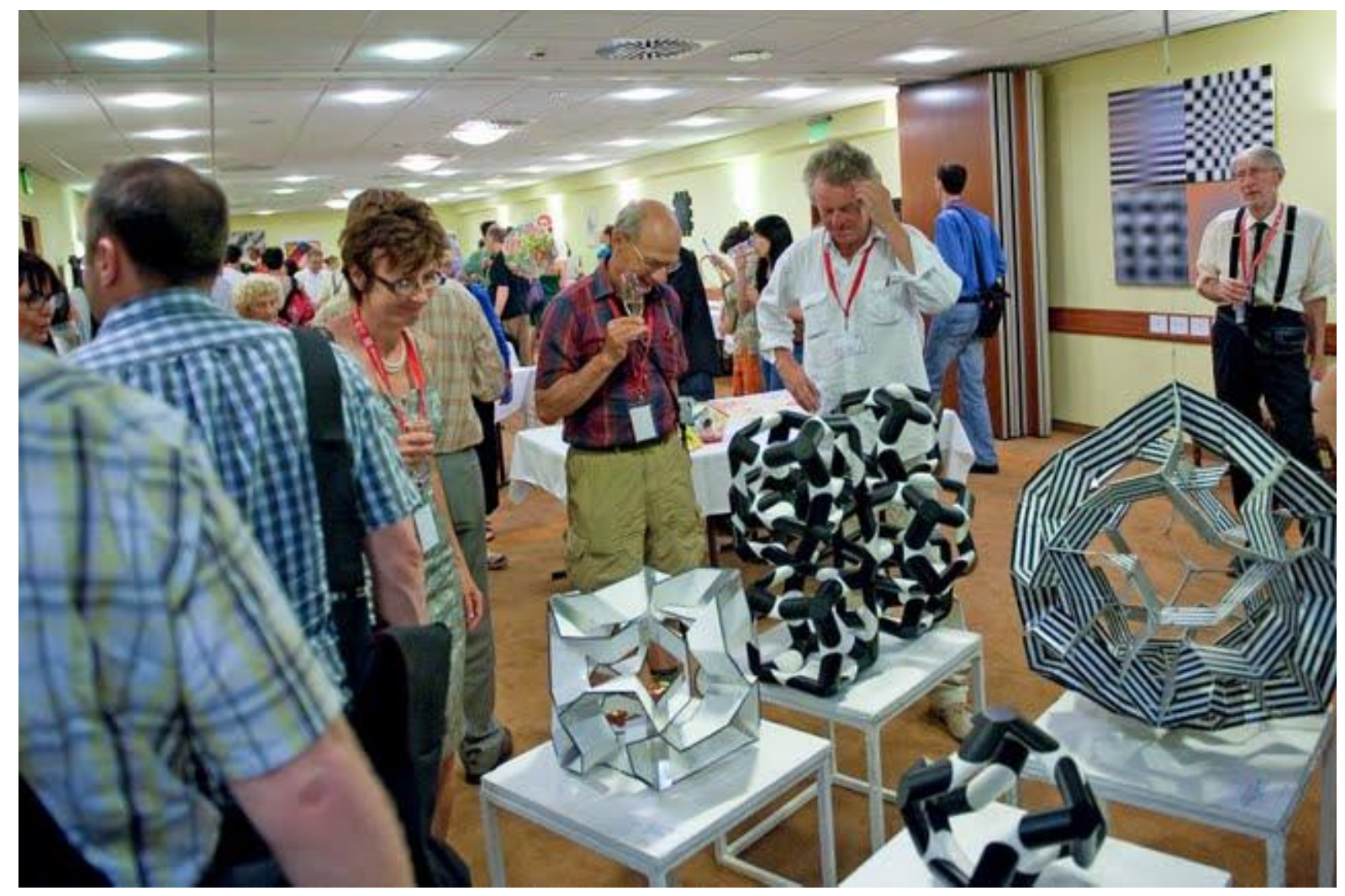

Figure 10: Artists, mathematicians and their mathematical artworks at Bridges 2010 Art Exhibit, curated by Robert Fathauer. Photo: László Mihály.

Bridges' transdisciplinary program has elaborated new transdisciplinary standards and has productively solved a high number of unforeseenable and unprecedented challenges. These are risks run by any truly transdisciplinary venture; they may never emerge in relatively homogeneus scientific or artistic communities with established traditions and history.

For example, Bridges has struggled to balance the openness of the conference and with academic legitimacy. In the beginning, Bridges conferences were highly inclusive; everybody who wanted to would have an opportunity to share their work. This model works in disciplines where journals are the true coin of the realm and conferences are just a chance to present work in progress to colleagues. But it can be problematic for participants from other disciplines-like Bridge's director Craig Kaplan's own field, Computer Science-, who want to assign significant weight to conference papers: "I think one of my influences has been to fight in favour of higher standards for regular papers, stricter peer review practices," Kaplans says. "Of course, it helped to set up online tools that streamlined the mechanics of reviewing so that we could focus on the quality. I think we've done a decent job of compensating for these changing standards by ensuring there are lots of other forums in which participants can present their work at the conference." 
The polyphonic nature of Bridges conferences requires an organic and open universe of polyphonic standards to ensure that each contribution will be judged according to the highest standards of its own field. If there is a new kind of need in the community, then a new platform is created for it. Different juries review the submissions for the art exhibits and the short film festival and there is a transdisciplinary program committee for reviewing the conference papers representing a multitude of scientific and artistic research fields.

Bridges has always had a core community of participants who make up the "choir". "And sure, we preach to them," admits Kaplan. He believes that designing a conference to appeal to its long-term supporters will make it better overall. But, like Bridges president Reza Sarhangi, Kaplan thinks that Bridges has done a good job of bringing in new faces, new voices, and new ideas every year. Bridges is increasingly offering itself as a public face for mathematics, a way to make it accessible to the general public. This was perhaps most successful in 2014, where Bridges was invited to Seoul by the International Congress of Mathematicians (ICM) to serve as a public counterpoint to the ICM happening across the city. Yet many mathematicians still don't see the special value in Bridges' polyphonic difference. "We need a stronger voice outside of Bridges itself. The Joint Mathematics Meetings (JMM) art exhibit and JMM math and art session are our attempts to reach others in the US in mathematics", Sarhangi says.

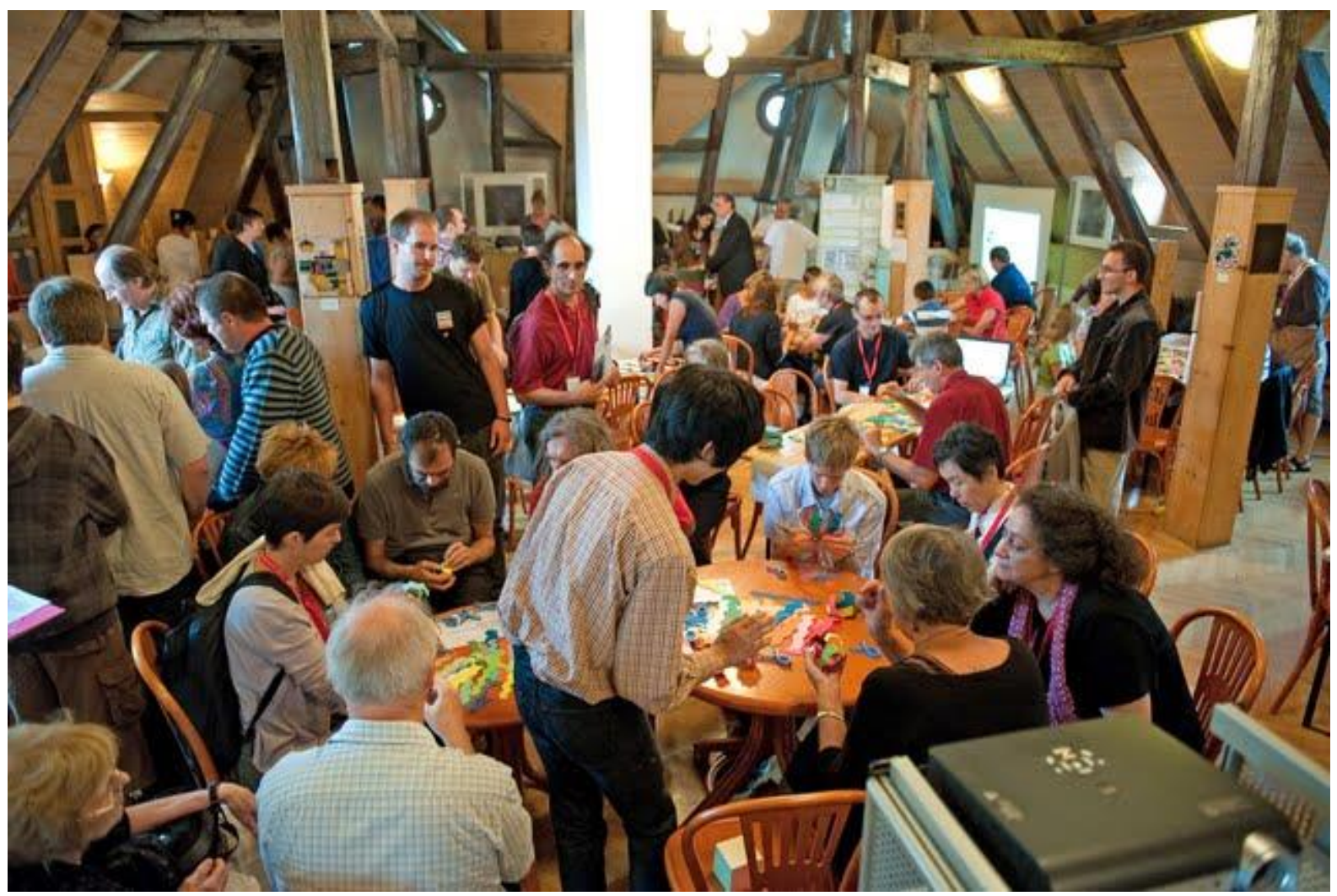

Figure 11: Dozens of fun activities at Bridges Family Day. Photo: László Mihály. 
Accepted manuscript for The Mathematical Intelligencer, ISSN: 0343-6993 (print version) ISSN: 1866-7414 (electronic version) The final publication is available at Springer via http://link.springer.com/article/10.1007/s00283-016-9630-9 DOI 10.1007/s00283-016-9630-9

\section{Bridges to the Future: the Next Generation}

Today, as changes in the world bring about unseen alterations in the structure of knowledge, any form of research, learning, or creativity capable of heightening awareness toward interlocking systems possesses untold value. First and foremost, knowledge such as this allows one to preserve a sense of exploration and inquiry, elements essential to all rational and creative activities. Without these, the ability to recognize those patterns and trends dictating current changes is lost.

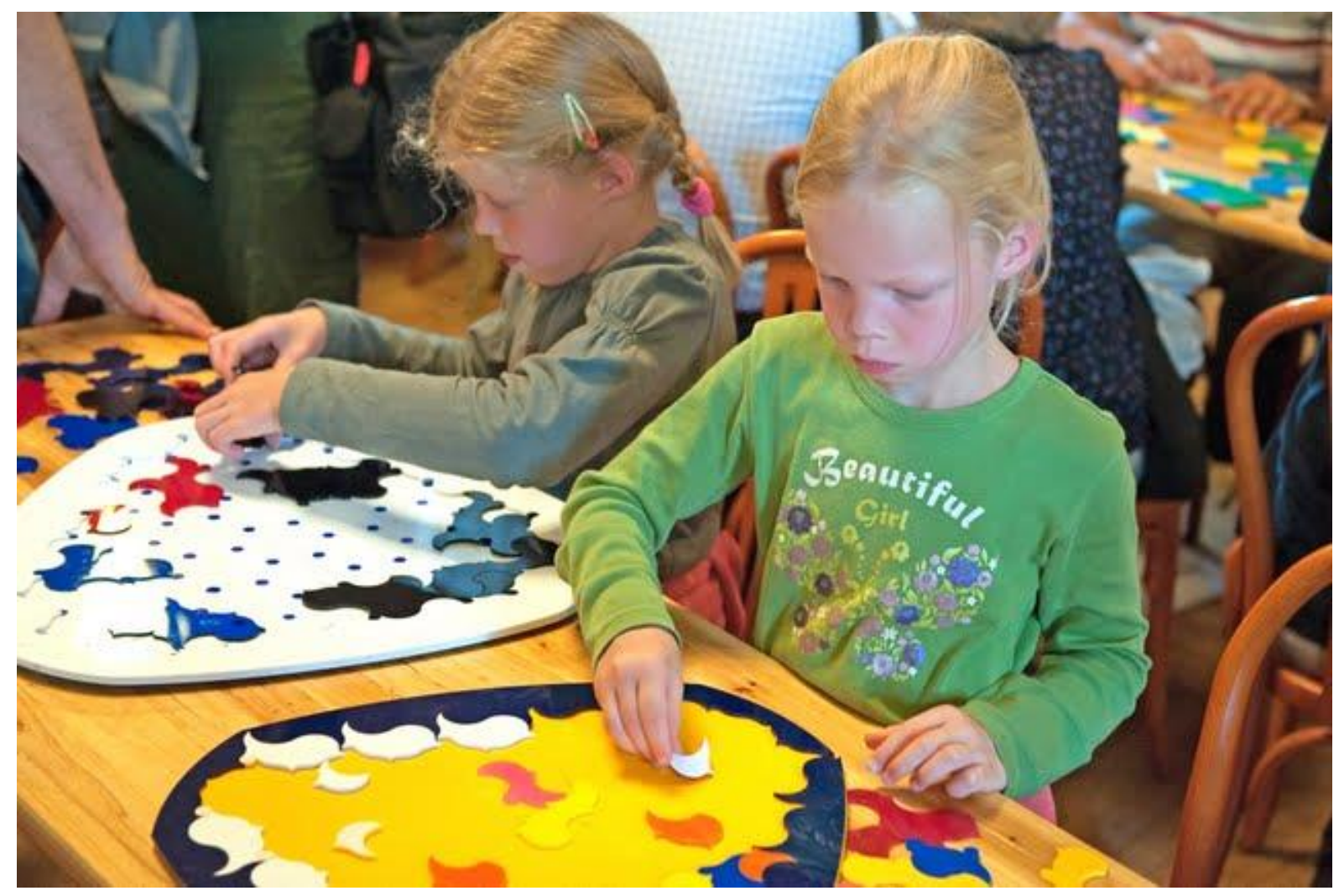

Figure 12: Girls playing with Gábor Gondos Bridges participant's math-art puzzle. Photo: László Mihály.

The first mathematical museum in the United States, MoMath ${ }^{26}$ was established in New York City to connect seemingly disparate phenomena while simultaneously encouraging creative and imaginative opportunities in math education for children and young adults. As one of the founding members of this internationally unique institute, George W. Hart not only adapted the Bridges community's STEAM-approach, but also the work of many distinguished Bridges members to this special, interactive setting.

Bridges Organization has combined forces in organizing the MoSAIC (Mathematics of Science, Art, Industry and Culture $)^{27}$ event series, sponsored by the Mathematical Sciences Research Institute (MSRI) to spur STEAM approach among young people. As a part of this program, popular aspects of Bridges events are held at university campuses throughout the 
Accepted manuscript for The Mathematical Intelligencer, ISSN: 0343-6993 (print version) ISSN: 1866-7414 (electronic version) The final publication is available at Springer via http://link.springer.com/article/10.1007/s00283-016-9630-9 DOI 10.1007/s00283-016-9630-9

USA. MoSAIC's astounding success and a new generation in the Bridges community suggest we have every reason for confidence.

\section{ACKNOWLEDGEMENTS}

Thanks to the Bridges Board of Directors for their information, to Maya Tóth, and to Osmo Pekonen and to my colleagues in the Bridges Finland 2016 Local Organizing Committee at the University of Jyväskylä.

University of Jyväskylä

Jyväskylä, Finland

e-mail: fenyvesi.kristof@gmail.com

Kristóf Fenyvesi, PhD - researcher of STEAM Learning and Contemporary Cultural Studies at University of Jyväskylä, Department of Art and Culture Studies; member of the Bridges Organization's Board of Directors, Director of Community Events; Chief Executive Officer of International Symmetry Association; Director of Experience Workshop International MathArt Movement.

\section{REFERENCES}

Belting, Hans. Florence and Baghdad: Renaissance Art and Arabic Science, Cambridge, MA: Belknap, 2011.

Böszörményi, István. “Klein-palackok síklapokból.” Ponticulus Hungaricus XVII. 3., 2013. March < http://members.iif.hu/visontay/ponticulus/rovatok/hidverok/boszeelte.html>

Christenson, Jerome. "Ramaley coined STEM term now used nationwide." Winonadailynews.com, November $\quad 13, \quad 2011$. $<$ http://www.winonadailynews.com/news/local/ramaley-coined-stem-termnow-used-nationwide/article 457afe3e-0db3-11e1-abe0-001cc4c03286.html> [Retrieved on 20.10.2015.]

Crease, Robert P. “Mathematical Bridges." Physics World, 2014, Volume 27, Number 07, 17.

Emmer, Michele, ed. Mathematics and Culture I-VI. Springer, 2004-2012. 
Accepted manuscript for The Mathematical Intelligencer, ISSN: 0343-6993 (print version) ISSN: 1866-7414 (electronic version)

The final publication is available at Springer via http://link.springer.com/article/10.1007/s00283-016-9630-9

DOI 10.1007/s00283-016-9630-9

--- , ed. Imagine Math(s) 1-3., Springer, 2012-2014.

---, ed. Imagine Math(s) 4. Unione Matematica Italia-Instituto Veneto di Scienze Lettere ed Arti, 2015.

Field, Mike. "Bridges London." A Notices of the AMS, 2006, Volume 54, Number 6, 730-732.

---, and Golubitsky, Martin. Symmetry in Chaos: A Search for Pattern in Mathematics, Art, and Nature. SIAM, 2009.

Gailiunas, Paul. "Transformations - the sculpture of István Böszörményi", Journal of Mathematics and the Arts, 1:4, 225-233

Gardner, Martin. "Mathematical Games", Scientific American 1978, 239 (5), 22-32.

Marcus, Solomon. "Review on Reza Sarhangi ed. 'Bridges: Mathematical Connections in Art, Music, and Science'." Nexus Network Journal, 1999, Volume I, 149-162.

Peterson, Ivars. "Swirling Seas, Crystal Balls: Spirals of Triangles Crinkle into Intricate Structures". Science News, 2009, Volume 170, Issue 17, 266-268.

Pickover, Clifford A. The Math Book: From Pythagoras to the 57th Dimension, 250 Milestones in the History of Mathematics. Sterling Publishing Company, Inc., 2009.

Sarhangi, Reza. "An Introduction to Medieval Spherical Geometry for Artists and Artisans." in Sarhangi, Reza and Sharp, John (ed.), Bridges London: Mathematics, Music, Art, Architecture, Culture. London: Tarquin Publications, 2006, 551-560.

---, and Martin, Bruce, D. "The Circle: A Paradigm for Paradox." in Reza Sarhangi (ed.), Bridges Conference. Winfield, Kansas: Southwestern College, 1998, 93-112.

Schattschneider, Doris. "Math and Art in the Mountains." Mathematical Intelligencer, 2006, Vol. 28, no. 3, 31-37.

Vörös, László. "Art in Shadows of the Six-Dimensional Cube." Proceedings of Bridges 2011: Mathematics, Music, Art, Architecture, Culture, 2011, 257-262.

\footnotetext{
${ }^{1}$ Bridges 2005's webpage: http://bridgesmathart.org/past-conferences/2005-2/ - Retrieved on 24.10.2015.

${ }^{2}$ See Alex Kasman's on-line database of mathematical fiction: $<$ http://kasmana.people.cofc.edu/MATHFICT/mfview.php?callnumber=mf538 $>$ - Retrieved on 24.10.2015.

${ }^{3}$ The play was inspired by Senechal's article "The Mysterious Mr. Ammann," The Mathematical Intelligencer, 26, 4, 2004, 10-21.

${ }^{4} \mathrm{Cf}$. "In the lobby outside the lecture hall, there were always a few children, participants, and spouses seated or kneeling on the floor, busy joining 3,720 ZomeTool connector balls to
} 
10,680 struts in modules that each hour were added to two growing monster models, [3D] shadows of the 4D cantellated 600-cell. David Richter and Daniel Duddy orchestrated the project." [Schattschneider, 2006: 32.]

${ }^{5}$ Cf. http://www.tandfonline.com/toc/tmaa20/current - Retrieved on 24.10.2015.

${ }^{6}$ On artistic consequences of connections between the European renaissance and the medieval Arabian science's visual investigations, see: Belting, 2011.

${ }^{7}$ See Reza Sarhangi's numerous articles on Abul Wafa al-Buzjani, e. g.: Sarhangi, 2006.

${ }^{8}$ Cf. http://www.isama.org/org/history.html - Retrieved on 24.10.2015.

${ }^{9}$ See the organization's website: http://www.isama.org/ - Retrieved on 24.10.2015.

${ }^{10}$ Research professor of Computer Science at Stony Brook University. Hart is also a sculptor whose work is recognized around the world for its mathematical depth and creative use of materials.

${ }^{11}$ Professor of Computer Science at the University of California, Berkeley. His works in computer graphics and in geometric design have provided a bridge to the world of art. In collaboration with several sculptors of abstract geometric art, Séquin has found a new interest and yet another domain where the use of computer-aided tools can be explored and where new frontiers can be opened through the use of such tools.

${ }^{12}$ Professor of University of Waterloo, editor of Journal of Mathematics and the Arts. The main focus of Kaplan's research is on the relationships between computer graphics, art, and design, with an emphasis on applications to graphic design, illustration, and architecture.

${ }^{13}$ A former researcher of Jet Propulsion Laboratory, and the founder of Tessellations, a company that specializes in products that combine art and mathematics. He is an internationally renowned author of activity books on art and mathematics and a mathematical artist, whose work has been shown in numerous exhibits in the U.S., Canada, and Europe.

${ }^{14}$ The virtual galleries of Bridges Art Exhibit can be accessed here: http://bridgesmathart.org/bridges-galleries/art-exhibits/ - Retrieved on 24.10.2015.

${ }^{15} \mathrm{Cf}$. http://www.nexusjournal.com/the-nexus-conferences.html - Retrieved on 24.10.2015.

${ }^{16} \mathrm{Cf}$. www.symmetry.hu and http://symmetry-us.com/ - Retrieved on 24.10.2015.

${ }^{17}$ Cf. http://www.math-art.eu/ - Retrieved on 24.10.2015.

${ }^{18}$ See: http://sigmaa.maa.org/arts/index.html - Retrieved on 24.10.2015.

${ }^{19}$ All Bridges proceedings can be downloaded from here:

http://www.archive.bridgesmathart.org - Retrieved on 24.10.2015.

${ }^{20}$ See < http://www.math.uconn.edu/ glaz/Mathematical Poetry at Bridges/index.html > Retrieved on 24.10.2015.

${ }^{21}$ From the many possible examples in the history of Bridges, see the case of the Spidronsystem introduced by the Hungarian designer Dániel Erdély and his international team first as an art project in Bridges Art Exhibits. Because of its geometrically interesting properties, the Spidron-system has also been featured later on a number of scientific forums, including as a cover-story of Science News (Peterson 2009) or in the The Math Book by Clifford A. Pickover (Pickover, 2009) and elsewhere.

${ }^{22}$ See www.bridgesmathart.org/bridges-2016/ - Retrieved on 24.10.2015.

${ }^{23}$ See www.experienceworkshop.hu - Retrieved on 24.10.2015.

${ }^{24}$ See, the complete list of Bridges conference reports: http://bridgesmathart.org/resources/conference-reports/ - Retrieved on 18.2.2016 ${ }^{25}$ See: http://bridgesmathart.org/past-conferences/ 
Accepted manuscript for The Mathematical Intelligencer, ISSN: 0343-6993 (print version) ISSN: 1866-7414 (electronic version) The final publication is available at Springer via http://link.springer.com/article/10.1007/s00283-016-9630-9 DOI 10.1007/s00283-016-9630-9

${ }^{26}$ See http://momath.org/ - Retrieved on 24.10.2015.

${ }^{27}$ See http://bridgesmathart.org/mosaic// - Retrieved on 24.10.2015. 